\title{
Valores geomorfológicos em áreas protegidas: o caso da Serra da Penha / Guimarães (Portugal)
}

\author{
Geomorphological values in protected areas: the case of Serra \\ da Penha / Guimarães (Portugal)
}

António Vieira, Centro de Estudos de Geografia e Ordenamento do Território, Universidade do Minho, Portugal, vieira@geografia.uminho.pt

(1) https://orcid.org/0000-0001-6807-1153

Francisco Costa, Centro de Estudos de Geografia e Ordenamento do Território, Universidade do Minho, Portugal, costafs@geografia.uminho.pt

(1) https://orcid.org/0000-0001-7041-7811

Letícia Corrêa, Universidade Federal de Santa Maria, Brasil, leticiarcorrea@gmail.com

(1) https://orcid.org/0000-0002-7372-3141

Resumo: A Serra da Penha localiza-se no município de Guimarães, atingindo os 613 metros de altitude e incluindo uma área verde de 50 hectares que, devido às suas características naturais, constitui um dos grandes pontos de atração turística municipal. No contexto das estratégias ambientais que têm vindo a desenvolver, a Câmara Municipal de Guimarães está a elaborar a classificação da Serra da Penha como Paisagem Protegida Local, proposta esta que deve ser entendida como uma medida de proteção e de valorização. Entre os valores naturais da Serra da Penha destacamos os valores geomorfológicos e geológicos, definidos como geossítios no Plano Diretor Municipal de Guimarães. A Serra da Penha apresenta um elevado valor e interesse geológico devido à sua natureza granítica, integrando também um conjunto diversificado de elementos geomorfológicos, com destaque para os grandes blocos dispersos nas vertentes (as penhas) e que podem vir a constituir um importante geopatrimónio a valorizar. A diversidade destes elementos é significativa, podendo-se encontrar blocos graníticos associados em formas diversificadas, com um arranjo particular, com configurações antropomórficas ou associados a determinados aspetos culturais e/ou religiosos, como seja o "penedo que abana", o "penedo suspenso" ou a gruta do ermitão. Assim, procuramos analisar a relevância dos valores geomorfológicos no âmbito do Geopatrimónio e seu enquadramento no processo de candidatura da Serra da Penha como Paisagem Protegida Local.

Palavras-chave: Património Geomorfológico; Geoconservação; Paisagem protegida; Serra da Penha.

Abstract: The Serra da Penha or Monte de Santa Catarina is located in the municipality of Guimarães, reaching 613 meters of altitude and including a green area of 50 hectares which, due to its natural characteristics, it's one of the great points of municipal tourist attraction. In the context of environmental strategies that have been developed, the Guimarães City Council is preparing the classification of the Serra da Penha as Local Protected Landscape, a proposal that should be understood as a measure of protection and valorization. Among the natural values of the Serra da Penha we highlight the geomorphological and geological values, defined as geosites in the Municipal Master Plan of Guimarães. The Serra da Penha has a high geological value and interest due to its granitic nature, also integrating a diverse set of geomorphological elements, highlighting the large blocks scattered in the slopes (the penhas) and which may constitute an important geoheritage to value. The diversity of these elements is significant and one can find associated granitic blocks in diverse shapes, with a particular arrangement, anthropomorphic configurations or associated with certain aspects, cultural and/or religious, such as the "waving rock", the "suspended rock" or the hermit's cave. With this work, we seek to analyze the relevance of geomorphological values within the Geoheritage and its framing in the application process of Serra da Penha as Local Protected Landscape.

Keywords: Geomorphological heritage; Geoconservation; Protected landscape; Serra da Penha. 


\section{Introdução}

O território correspondente ao município de Guimarães sofreu, ao longo dos tempos, uma evolução bastante apoiada numa íntima inter-relação entre o Homem e a Natureza. Desde cedo, espaços verdes e cursos de água se tornaram recursos fundamentais para as atividades humanas, nomeadamente a agricultura, a silvopastorícia e as próprias indústrias tradicionais. Para além disso, serviu também, de forma ímpar, como fator de lazer e bem-estar, religioso e cultural (Vieira et al., 2019).

Uma caraterística fundamental deste território é a significativa dispersão dos espaços edificados, correspondendo a um padrão de ocupação do espaço caraterístico do noroeste de Portugal, favorecido pelos condicionalismos histórico-sociais e das caraterísticas físicas e do clima. Consequentemente, a paisagem apresenta-se bastante fragmentada, observando-se um predomínio dos padrões de urbanização e industrialização difusos, onde a plurifuncionalidade do uso do solo se interconecta (Bento-Gonçalves et al., 2011).

Apoiando-se nesta matriz basilar, o Município de Guimarães tem desenvolvido, ao longo das últimas três décadas, um conjunto de iniciativas, integradas numa política de revitalização e promoção do território a nível económico, social e ambiental.

A nível ambiental, dentre as múltiplas iniciativas implementadas, podem destacar-se a criação de diversos parques urbanos, vias cicláveis no município ou a candidatura ao galardão de Capital Verde Europeia, complementando-se numa estratégia global que pretende fazer do município de Guimarães um território verdadeiramente sustentável. Ainda que esta última iniciativa não tenha tido o sucesso total, constituise como uma alavanca para atingir o desígnio da sustentabilidade ambiental, potenciando novas iniciativas.

Uma das medidas que estava já equacionada era a valorização da Serra da Penha e a sua instituição como área protegida. Limitando a sudeste a cidade de Guimarães, a Serra da Penha é um relevo imponente, maioritariamente florestado, local de culto à Nossa Senhora do Carmo e destino de muitas romarias e de intenso fluxo turístico.

Nas últimas décadas a Serra da Penha, e especificamente o espaço da Irmandade da Penha, foi alvo de intervenções no sentido de valorizar o seu potencial paisagístico e de biodiversidade, a par da dotação de infraestruturas e equipamentos de apoio ao usufruto daquele espaço.

As estratégias de valorização do património biológico passaram pela eliminação progressiva das espécies não autóctones (especialmente do Eucaliptus globulus e Pinus pinaster) e sua substituição por espécies arbóreas autóctones (em particular os Quercus faginea, Quercus robur e Castanea sativa), mas também por uma ação contínua de limpeza e manutenção do espaço florestal, providenciando condições de menor vulnerabilidade e maior resiliência face aos incêndios florestais, problema extremamente grave em Portugal e especialmente no noroeste de Portugal. Estas medidas permitiram a manutenção de uma área verde contínua de cerca de 60 
hectares, maioritariamente composta de espécies autóctones, mas também com um conjunto importante de espécies exóticas (não invasoras).

É neste contexto e com condições ambientais e culturais bastante relevantes, que se enquadra a proposta de criação de uma área de Paisagem Protegida Local, figura legal que enquadra propostas de delimitação e constituição de áreas protegidas de âmbito regional ou local.

Considerado elemento integrante e caraterizador da paisagem da Serra da Penha e fundamental para a sua valorização natural, foi proposta a integração dos elementos do geopatrimónio. Em boa verdade, os elementos da geodiversidade constituem o suporte da vida (Vieira, Cunha, 2008), asseguram a sustentação ecológica dos recursos bióticos (Figueiró et al., 2013) e das próprias atividades humanas. Contudo, a sua conservação é de extrema importância também pelo facto destes elementos constituírem um testemunho insubstituível da história da Terra e, consequentemente, do próprio Homem (Vieira, Cunha, 2004).

O geopatrimónio integra, no nosso entendimento, os elementos patrimoniais de natureza geológica, geomorfológica, hidrológica e pedológica, podendo incluir-se, eventualmente, outras dimensões da geodiversidade.

A problemática da geodiversidade apenas na década final do século $X X$ ganhou projeção, com os trabalhos Sharples (1993) ou Dixon (1995) e mais tarde, mais amplamente difundida, por exemplo, pelos trabalhos de Gray (2004; 2013), o mesmo acontecendo especificamente com o Património Geomorfológico, promovidos pelos trabalhos de Panizza e Piacente (Panizza, Piacente, 1993, 2003), Grandgirard (1997), Reynard e Pralong (Reynard, Panizza, 2005; Reynard, 2005; Pralong, 2006), Cendrero (1996) ou Serrano e Trueba (2005), só para citar alguns que maior alcance obtiveram pela pertinência das suas propostas.

Ainda que o objetivo da proposta de criação da área de Paisagem Protegida da Serra da Penha seja a inclusão das diversas dimensões do geopatrimónio, neste trabalho iremos debruçar-nos apenas sobre o Património Geomorfológico, que tem aqui uma expressão enorme, sendo inclusivamente responsável pela designação da serra, da "Penha", pela existência de inúmeros amontoados de grandes blocos graníticos, regionalmente designados de penhas.

A inventariação de elementos geomorfológicos na serra da Penha revelou um conjunto bastante diversificado e dotado de relações intensas com a ocupação humana, secular, atribuindo-lhes muitos valores além dos estritamente geomorfológicos ou geopatrimoniais.

Consequentemente, este trabalho apoiar-se-á em conceitos e metodologias por nós desenvolvidos em trabalhos anteriores (Vieira, 2008, 2014; Vieira et al., 2014), pelo que consideraremos que os Sítios Geomorfológicos ou Geomorfossítios, entendidos no seu conjunto como Património Geomorfológico, são elementos geomorfológicos constituídos por formas do relevo, processos e depósitos correlativos, desenvolvidos a várias escalas, aos quais se atribui um conjunto de valores (científico, estético, 
cultural, ecológico e económico) decorrentes da perceção humana. Neste sentido, estes elementos geomorfológicos, apresentando elevado valor patrimonial, devem ser objeto de proteção legal e promoção cultural, científico-pedagógica e para atividades de lazer, desporto e turismo.

Selecionando apenas um número reduzido de elementos geomorfológicos inventariados, evidenciaremos neste trabalho as potencialidades geopatrimoniais existentes na Serra da Penha.

\section{Caraterização da área de estudo}

O Município de Guimarães localiza-se no noroeste de Portugal continental, integrando, do ponto de vista administrativo, o distrito de Braga e a NUT III AVE, encontrando-se dividido em 48 freguesias (Figura 1). O seu território ocupa uma área de $240,95 \mathrm{Km}^{2}$, sendo limitado a norte, noroeste e sudeste por áreas mais elevadas, como a Falperra, o Sameiro e a Penha, correspondendo esta última ao ponto mais elevado do município, com 613 metros de altitude. O clima presente é mediterrâneo, mas com significativa influência atlântica, traduzindo-se num clima de temperaturas amenas, com pequenas amplitudes térmicas e forte pluviosidade média.

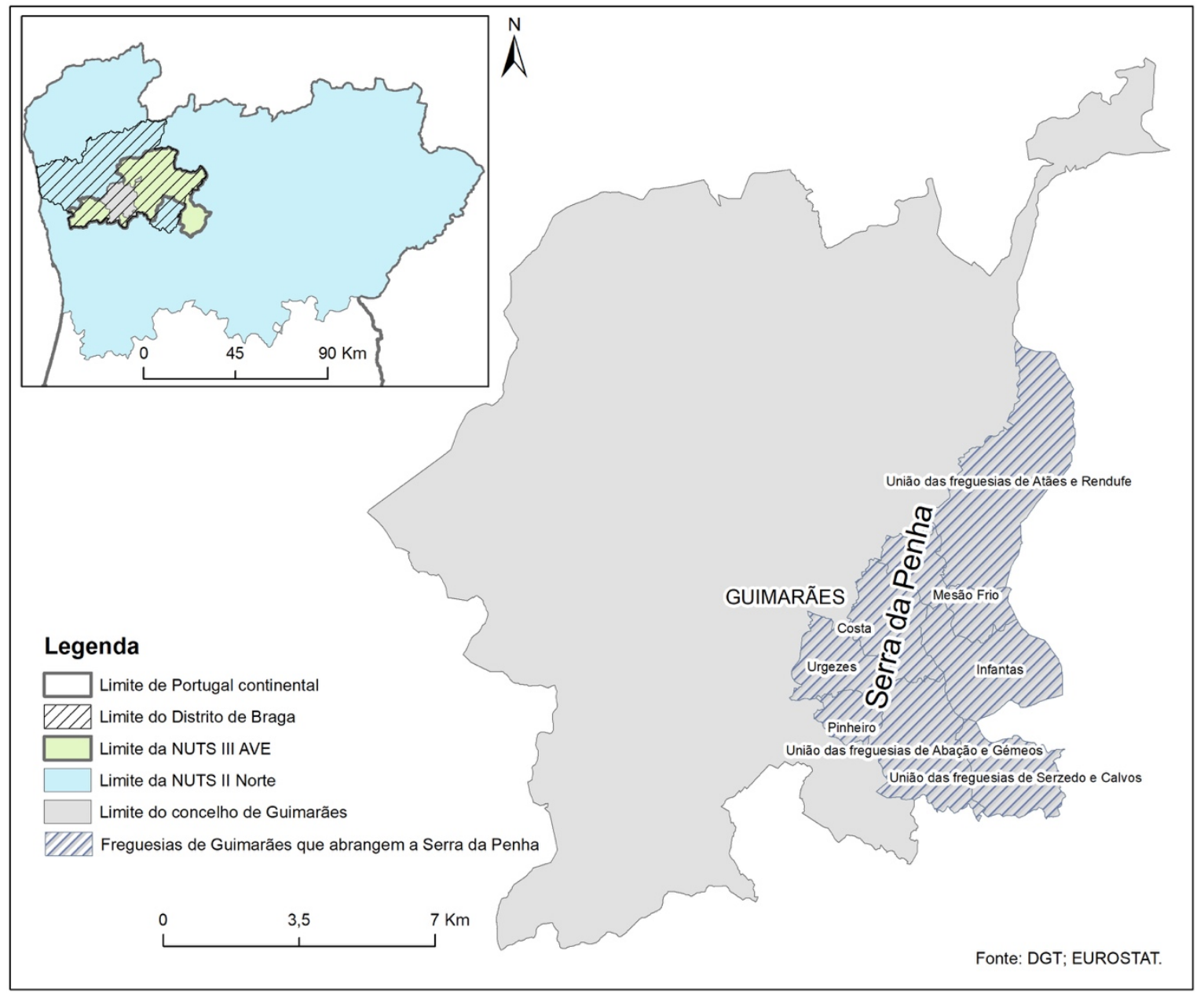

Figura 1: Localização do Município de Guimarães e Serra da Penha. 
Este território era habitado por 158.124 indivíduos, segundo os Censos de 2011, dos quais 76.774 do sexo masculino e 81.350 do sexo feminino.

A Serra da Penha corresponde a um maciço essencialmente granítico, com orientação NNE-SSW, posicionado a sudeste da cidade de Guimarães e atualmente densamente arborizado.

Estende-se por 8 freguesias do concelho de Guimarães - Abação, Atães, Calvo, Costa, Infantas, Mesão Frio, Pinheiro - cobrindo uma área de cerca de 1140 ha (Figura 1). Em termos morfológicos, a Serra da Penha contata com o vale de Atães a norte, com o monte de Santa Marinha a este, com o vale do Selho a noroeste, e com a Senhora do Monte a sudoeste (Oliveira, 2001).

O topo da Penha (que atinge a altitude máxima aos $613 \mathrm{~m}$ ) apresenta uma forma aplanada, orientado no sentido N-S, com cerca de $1,5 \mathrm{~km}$ de comprimento e $300 \mathrm{~m}$ de largura (Figura 2 e 3). Aqui, abundam grandes monólitos de granito, de forma boleada pela intensa erosão (as penhas; Oliveira, 2001).

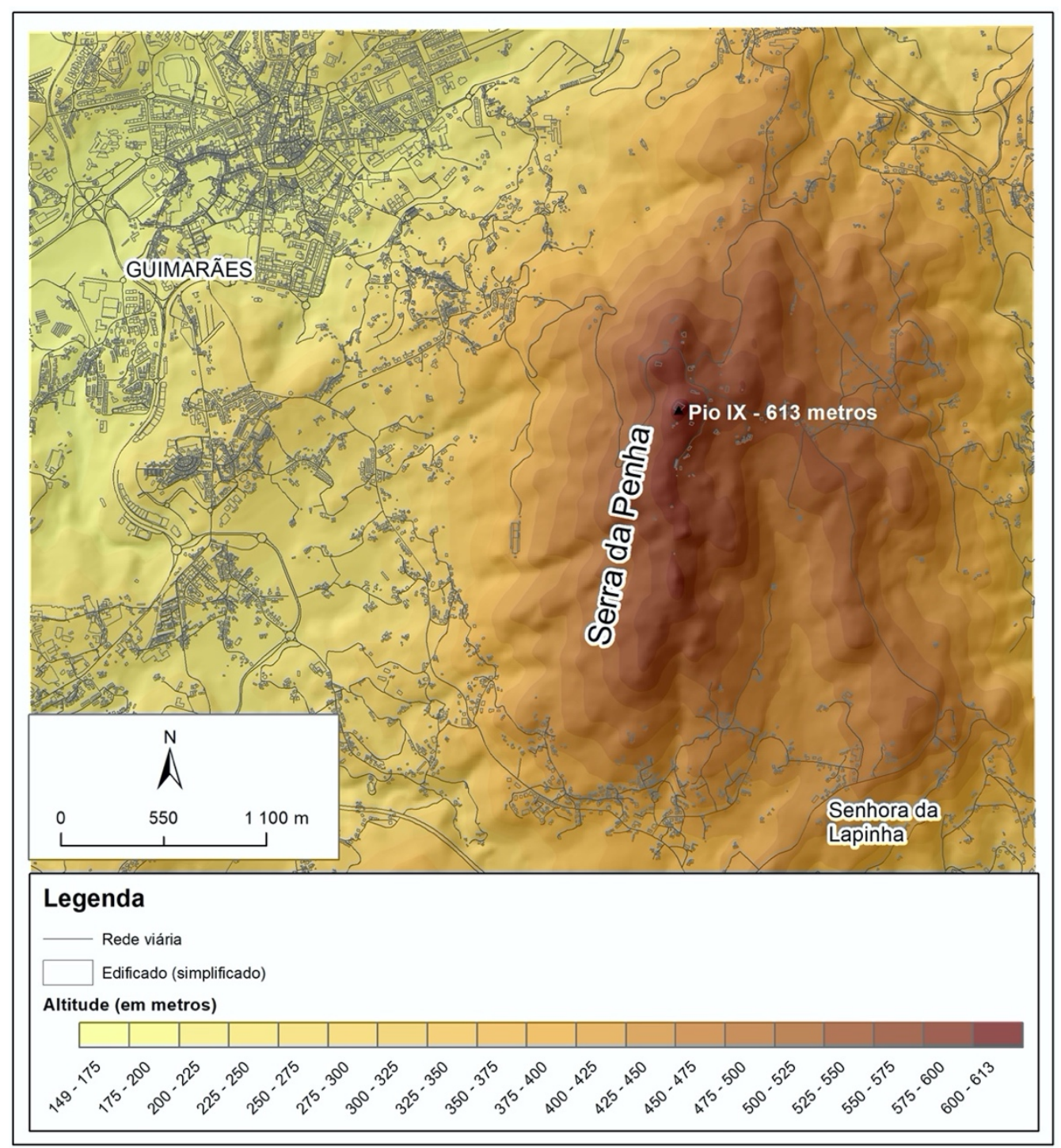

Figura 2: Esboço hipsométrico da Serra da Penha. 
Uma das principais características do relevo desta área é a sua significativa amplitude altimétrica (entre os 195 metros e os 613 metros) associada a vertentes moderadamente declivosas, sendo que grande parte da área se situa entre os $16 \mathrm{e}$ os $40 \%(62,05 \%$ da área da serra).

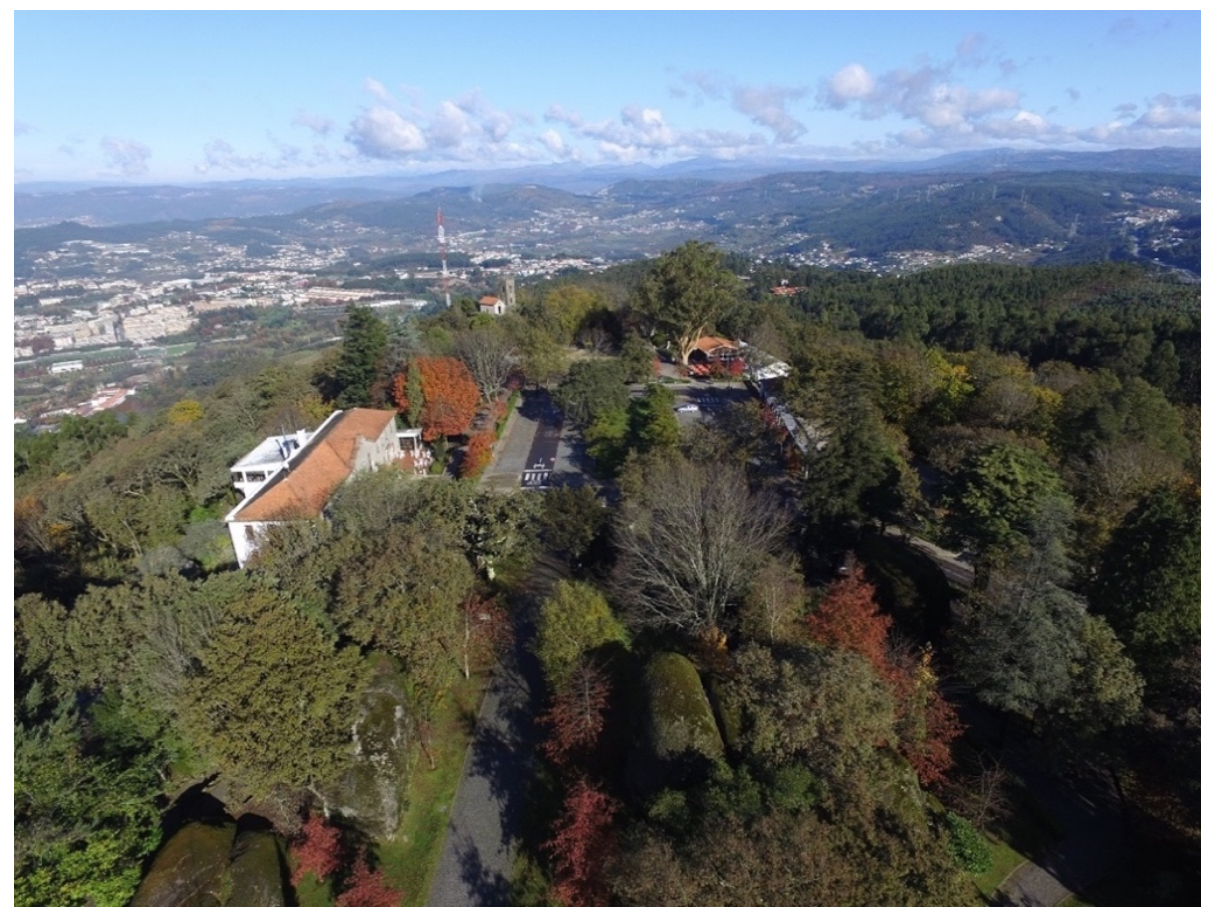

Figura 3: Vista aérea sobre a Serra da Penha.

\section{A promoção da Serra da Penha a paisagem protegida local}

Como referido anteriormente, a iniciativa de criação de uma área protegida no município de Guimarães surgiu na sequência das políticas de sustentabilidade ambiental promovidas pelo executivo municipal e ganhou relevância no contexto da candidatura ao galardão de Capital Verde Europeia.

Consequentemente, considerando-se a Serra da Penha como espaço com valores naturais de elevado valor, avaliou-se a possibilidade de definição de uma área protegida com estatuto de Paisagem Protegida Local.

A área da Serra da Penha está abrangida já por algumas medidas de proteção ao nível da gestão do território municipal, uma vez que na Carta de Ordenamento do Plano Diretor Municipal de Guimarães se encontra classificada em diversas categorias: Espaços florestais de proteção, Espaços agrícolas, Espaços destinados a equipamentos e infraestruturas e Estrutura Ecológica Municipal, Nível I e II, Locais de interesse geológico, Sítio arqueológico, Património Edificado e Linhas de telecomunicações.

No que diz respeito ao enquadramento legal para classificação como Paisagem Protegida Local, a candidatura é enquadrada pelo Decreto-Lei $n^{\circ}$ 242/2015, de 15 de 
outubro, que altera o Decreto-Lei $n^{\circ} 142 / 2008$, de 24 de julho, que determina que todo o território classificado contenha paisagens resultantes da interação harmoniosa do ser humano e da natureza, e que evidenciem grande valor estético, ecológico ou cultural. Neste contexto, a classificação de uma paisagem protegida visa a proteção dos valores naturais e culturais existentes, realçando a identidade local, e a adoção de medidas compatíveis com os objetivos da sua classificação (cf. o artigo $19 .^{\circ} \mathrm{n} \cdot{ }^{\circ} 1$ e 2 do Decreto-Lei n. ${ }^{0}$ 142/2008, de 24.07, alterado pelo Decreto-Lei n ${ }^{\circ}$ 242/2015, de 15.10 que aprova o Regime Jurídico da Conservação da Natureza e da Biodiversidade - RJCNB).

A área proposta para implementação de Paisagem Protegida Local tem uma dimensão de cerca de 122 ha, englobando toda a propriedade da Irmandade da Penha e propriedades no seu entorno, que funcionam como uma zona tampão, e se encontram limitadas por estradas, caminhos, limites de propriedades, definindo uma área alongado no sentido Norte-Sul (Figura 4).

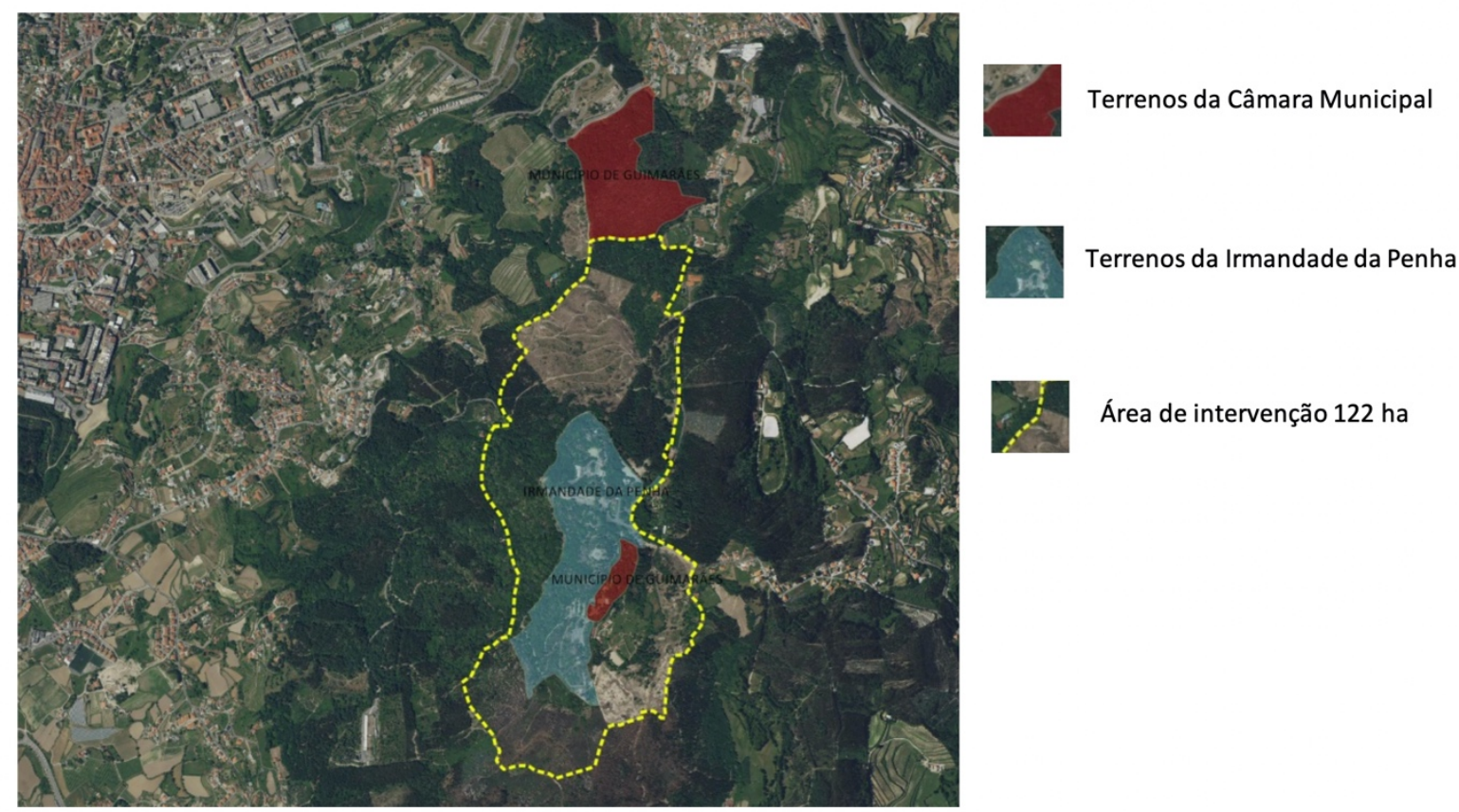

Figura 4: Delimitação da área proposta para Paisagem Protegida Local (adaptada de Meireles et al., 2017).

O projeto de proposta de criação da área protegida de âmbito local integra quatro objetivos gerais (Meireles et al., 2017):

- objetivo geral 1: sensibilizar e envolver a sociedade civil, a opinião pública e os agentes locais para a urgência da melhoria da qualidade ambiental da montanha da penha;

- objetivo geral 2: Recuperar, melhorar e conservar o habitat; 
- objetivo geral 3: Salvaguarda do ecossistema com a valorização das espécies autóctones. Diminuir a pressão das espécies exóticas nas áreas de distribuição da Montanha da Penha;

- objetivo geral 4: melhorar o estatuto de conservação da natureza, biodiversidade e geodiversidade na montanha da penha.

Nestes objetivos, os valores da geodiversidade são enunciados, embora de certa forma subalternizados em relação aos demais elementos presentes, nomeadamente os da biodiversidade, ainda que os primeiros sejam fundamentais para viabilidade dos segundos (Vieira, Cunha, 2004; Vieira, 2008).

Com efeito, no objetivo 1 é proposta uma medida, a medida 1.2, direcionada para a promoção do trabalho de monitorização e novos estudos sobres os valores naturais e culturais e propondo as seguintes ações:

- Criação de incentivos à realização de novos estudos e à promoção dos mesmos;

- Avaliação do estado de conservação dos valores existentes;

- Valorizar o património natural, paisagístico, histórico-cultural e geológico numa perspetiva educativa e científica através de intervenções direcionadas para a experimentação e/ou demonstração e para o aproveitamento e/ou instalação de infraestruturas e equipamentos;

- Valorizar a vertente turística da paisagem numa lógica recreativa e lúdica, através da regulação de atividades ao ar livre (desportivas e/ou observação) compatíveis com os valores existentes

Já no objetivo 4, a medida 4.2, em que se propõe potenciar e valorizar a geodiversidade com medidas de apoio à Geopreservação da Montanha da Penha, definem-se as seguintes ações:

- Conservar e assegurar a manutenção da geodiversidade;

- Interpretar a geodiversidade para os visitantes de áreas protegidas e contribuir para a manutenção da biodiversidade e dos processos ecológicos dependentes da geodiversidade;

- Para uma melhor inclusão da geodiversidade em diferentes ações de conservação da natureza é importante promover a utilização sustentável dos recursos geológicos;

- Introdução do conhecimento geológico nos instrumentos de ordenamento das áreas protegidas;

- Levantamento dos locais de interesses geológico, geomorfológico e paleontológico ou arqueológico que ocorram no interior das áreas protegidas; 
- Integração da política de conservação da natureza e do princípio da utilização sustentável dos recursos geológicos na política de ordenamento do território e nas diferentes políticas setoriais;

- Incentivar ao desenvolvimento de projetos de educação ambiental em matéria de conservação da natureza, em escalas municipal e local;

- Proteger e manter a integridade dos locais com relevância em termos de geoconservação, minimizando os impactos adversos dos locais importantes em termos de geoconservação;

- Preservar os maciços rochosos e habitats rupícolas associados, de forma a assegurar a conservação do habitat de espécies da flora rupícola e/ou por serem essenciais para a nidificação de algumas espécies de aves.

\section{Valor geopatrimonial da Penha}

A Serra da Penha apresenta um elevado e diversificado número de elementos integrantes da geodiversidade com caraterísticas geopatrimoniais. Desde os elementos geológicos, correspondentes às caraterísticas intrínsecas das rochas granitoides presentes, aos elementos geomorfológicos de que se destacam as penhas, e também os hídricos, como são as minas de água da Serra da Penha, que ainda atualmente abastecem a cidade. A todos eles podemos acrescentar um conjunto de caraterísticas de âmbito cultural e ecológico, decorrente da relação de longa data estabelecida com o Homem. Com efeito, o desenvolvimento de intensas relações entre as atividades humanas e o espaço da Serra da Penha, nomeadamente as de caráter religioso (já de longa data) e, mais recentemente, as de lazer, contribuíram para a construção de uma imagem multifacetada daquele lugar, concedendo-lhe um simbolismo junto da população que ultrapassa a simples dimensão física e natural. Neste contexto, os elementos da geodiversidade (nomeadamente os geomorfológicos) ganham um simbolismo e uma valorização que vai para além das suas caraterísticas intrínsecas, integrando valores culturais, religiosos, históricos e estéticos. Consequentemente, os elementos da geodiversidade aqui presentes constituem fatores de valorização da própria paisagem, incorporando dimensões para além da puramente científica.

\subsection{Metodologia de Avaliação do Património Geomorfológico}

No contexto da iniciativa de promover a Serra da Penha a Paisagem Protegida Local, e tendo presente o interesse em valorizar os elementos da geodiversidade existentes no âmbito da proposta, considerámos importante ter em conta e estabelecer uma metodologia para a identificação e avaliação do Património Geomorfológico existente na área definida. Assim, na sequência de trabalhos anteriormente desenvolvidos nesta temática, propomos a implementação de uma metodologia semi-quantitativa (Vieira 2008; 2014), que pressupõe a realização de uma identificação inicial das geoformas e uma avaliação qualitativa (subjetiva), que permita uma inventariação dos elementos geomorfológicos a caraterizar e a submeter à avaliação geopatrimonial. Posteriormente é aplicada uma metodologia de avaliação quantitativa. 
Com base na metodologia proposta, seleciona-se um conjunto de critérios (valores inerentes ao património geomorfológico) necessários para a avaliação, englobados em três indicadores principais: o intrínseco (valor científico), o adicional (que integra os valores cultural, ecológico, estético e económico) e o de uso e gestão.

No que diz respeito ao Valor Intrínseco (correspondente ao valor científico), são considerados os seguintes critérios: a raridade, a diversidade, a representatividade, a integridade e o conhecimento científico sobre os sítios. Relativamente ao Valor Adicional, este integra quatro dimensões valoráveis (cultural, estética, ecológica e económica), pelo que para o valor cultural, os critérios considerados são a importância histórico-arqueológica, a importância religiosa/espiritual e evento artístico/cultural. No respeitante ao valor ecológico, os critérios selecionados são a diversidade ecológica, importância ambiental e ocorrência de habitats específicas. Para o valor económico consideram-se os critérios importância turística, importância desportiva / prática desportiva e existência de itinerário turístico/cultural. Quanto ao valor estético, cabe a seleção dos critérios diversidade paisagística, presença de água, contraste de cor e presença de elementos não harmónicos.

Finalmente, no que respeita ao valor de uso e gestão, os critérios adotados são os seguintes: acessibilidade, vulnerabilidade, proteção, condições de observação e intensidade de uso.

Cada um dos critérios é avaliado numa escala de 0 a 1, posteriormente somados dentro de cada valor e divididos pelo número de critérios considerados, de acordo com a seguinte metodologia:

$$
V I=(\text { critério } 1+\text { critério } 2+\ldots \text { critério } n) / \text { total de critérios }
$$

em que VI corresponde ao Valor Intrínseco;

$$
V A=(\text { critério } 1+\text { critério } 2+\ldots \text { critério } n) / \text { total de critérios }
$$

em que VA corresponde ao Valor Adicional;

$$
V U=(\text { critério } 1+\text { critério } 2+\ldots \text { critério } n) / \text { total de critérios }
$$

em que VU corresponde ao Valor de Uso e Gestão.

O Valor Total (VT) é calculado pelo somatório dos três Valores anteriormente calculados, divididos por três:

$$
V T=(V I+V A+V U) / 3
$$

Desta forma, o Valor Total corresponde a um valor ponderado, traduzido por um índice em que os elementos de maior valor patrimonial se aproximarão de 1 e os de menor valor estarão mais próximos de 0 .

\subsection{Avaliação dos Sítios Selecionados}

Com base no conhecimento que temos da Serra da Penha e em trabalhos aqui já desenvolvidos (Oliveira, 2001; Pinto, 2011), selecionámos para este trabalho os seguintes elementos geomorfológicos: 
a) O Penedo suspenso (Figura 5) corresponde a um amontoado de blocos de grandes dimensões, configurando uma forma granítica de tipo 'tor', em que um dos blocos se encontra apoiado nos adjacentes, não se encontrando em contato com o solo. Instalado sobre estes blocos, encontra-se uma capela (onde se faz a devoção a S. Cristóvão da Penha, padroeiro dos motoristas) e torre.

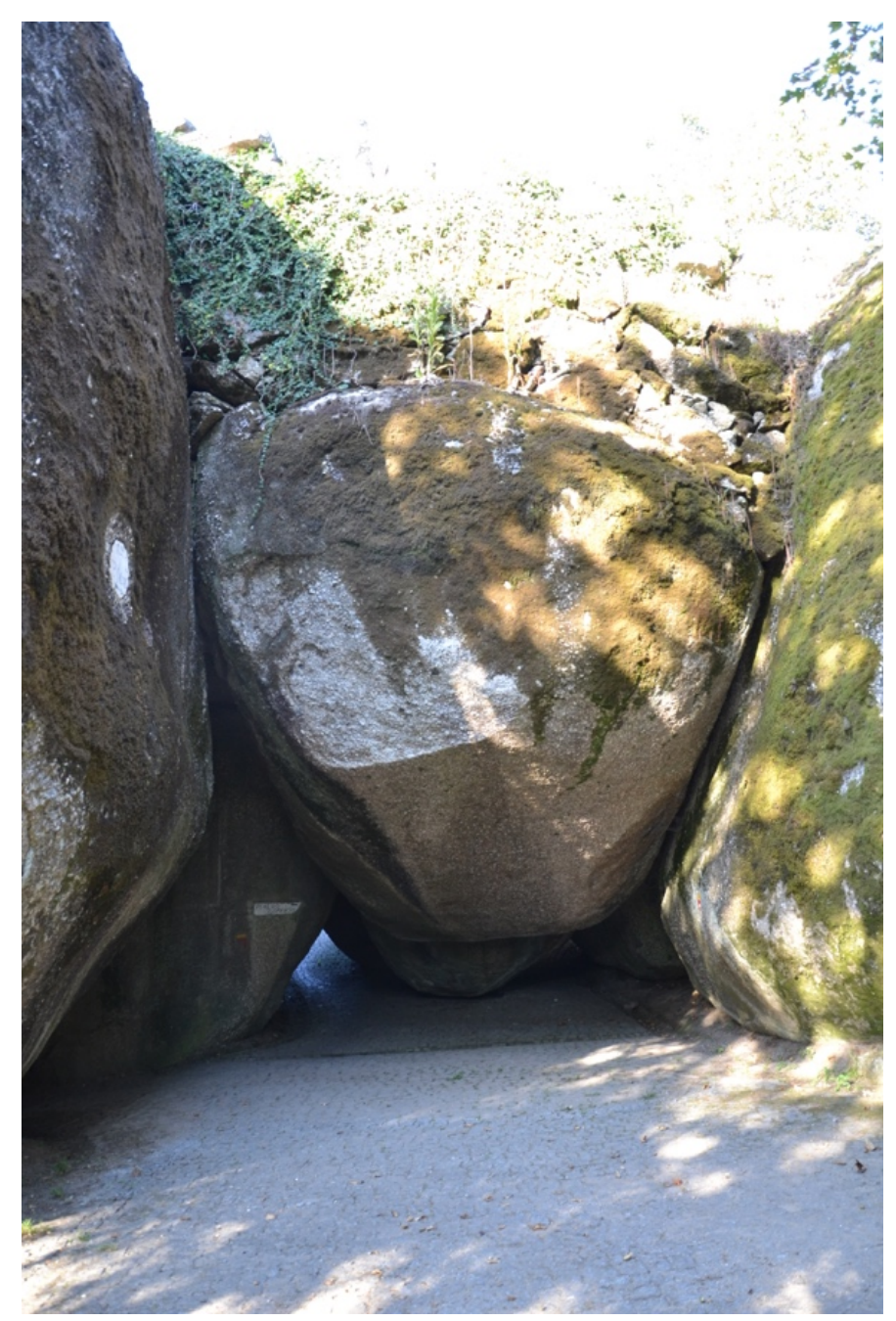

Figura 5: Penedo suspenso.

b) O Desfiladeiro labiríntico (Figura 6) corresponde a um conjunto de caminhos interligados, de largura reduzida, que serpenteia em volta de diversos blocos graníticos de grande dimensão (o conjunto de blocos constitui o que localmente se designa por penhas). 


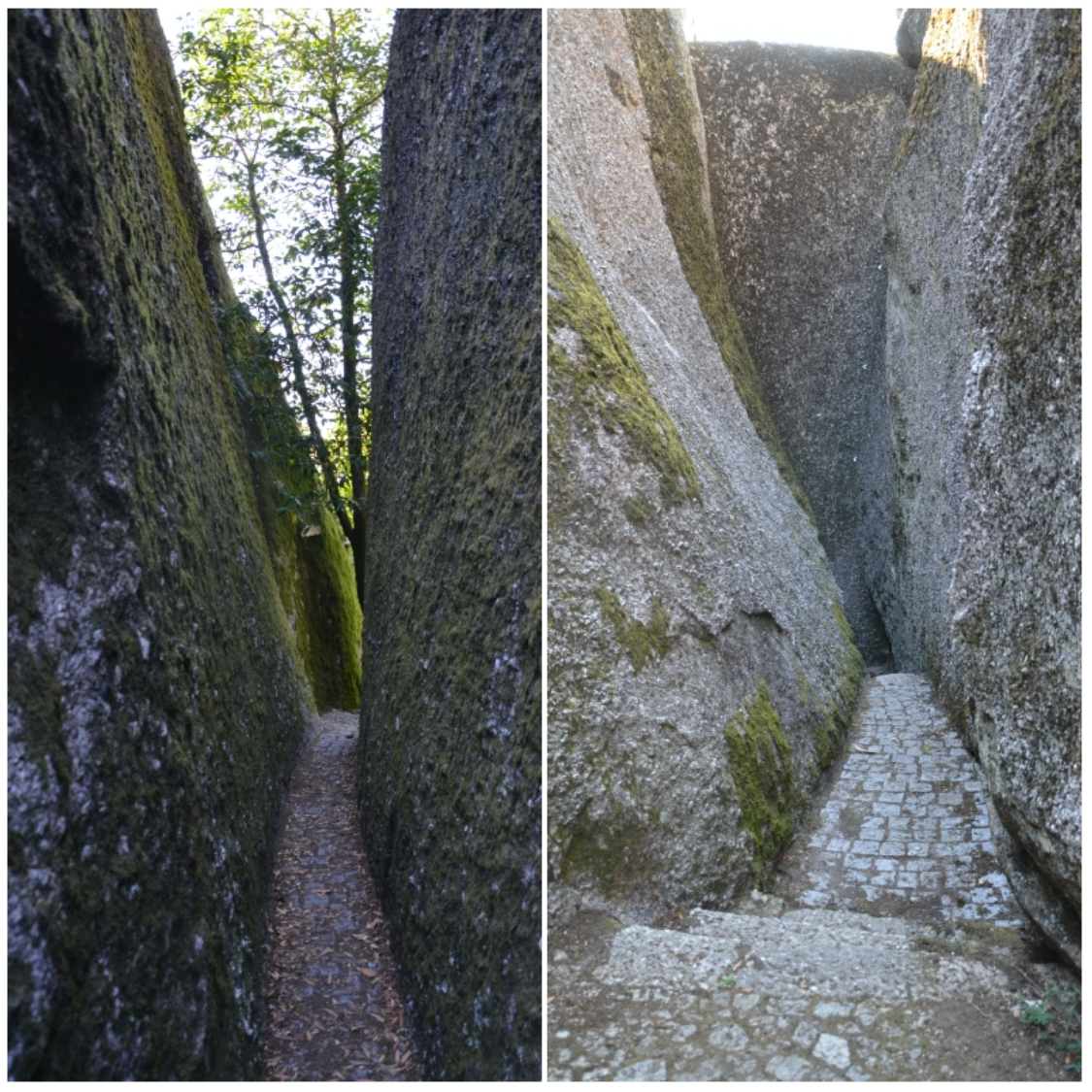

Figura 6: Dois aspetos do desfiladeiro labiríntico.

c) A Pedra que abana (Figura 7) é um bloco granítico de dimensões consideráveis, que se encontra em situação de instabilidade na superfície em que repousa. Quando impulsionado em determinado ponto, o bloco balouça, daí a designação de pedra que abana.

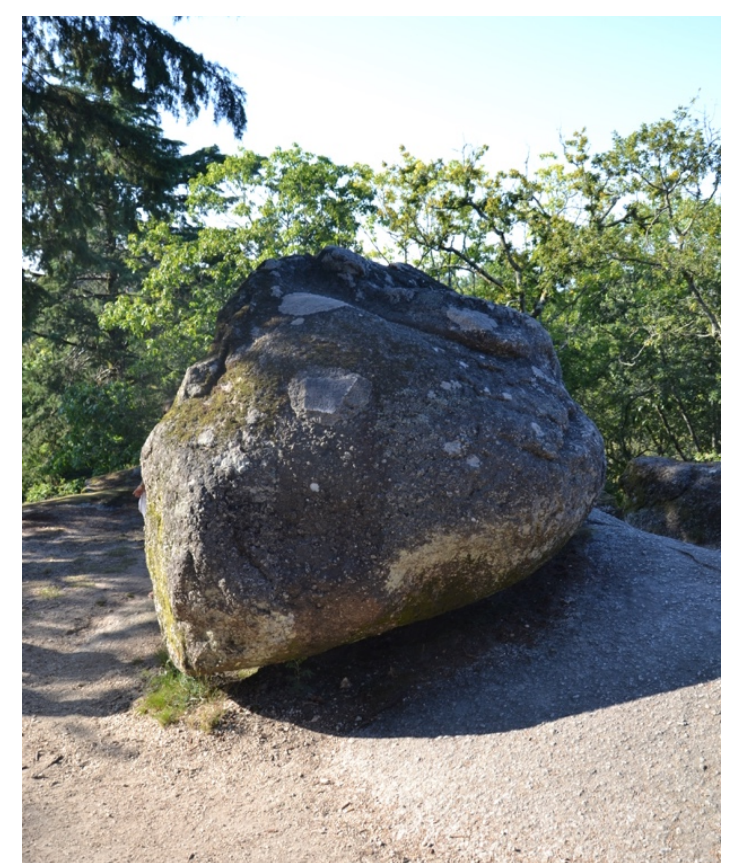

Figura 7: Pedra que abana. 
d) A Gruta de Nossa Senhora de Lurdes corresponde a uma forma granítica de tipo tor, cuja configuração e posicionamento dos blocos define um pequeno abrigo em rocha, utilizado como local de oração e adoração à Nossa Senhora de Lurdes. Neste local, nos finais do século XIX e inícios do século XX, realizavam-se cerimónias religiosas e efetuavam-se romarias, sendo um local carregado de grande simbolismo e associado a práticas religiosas.

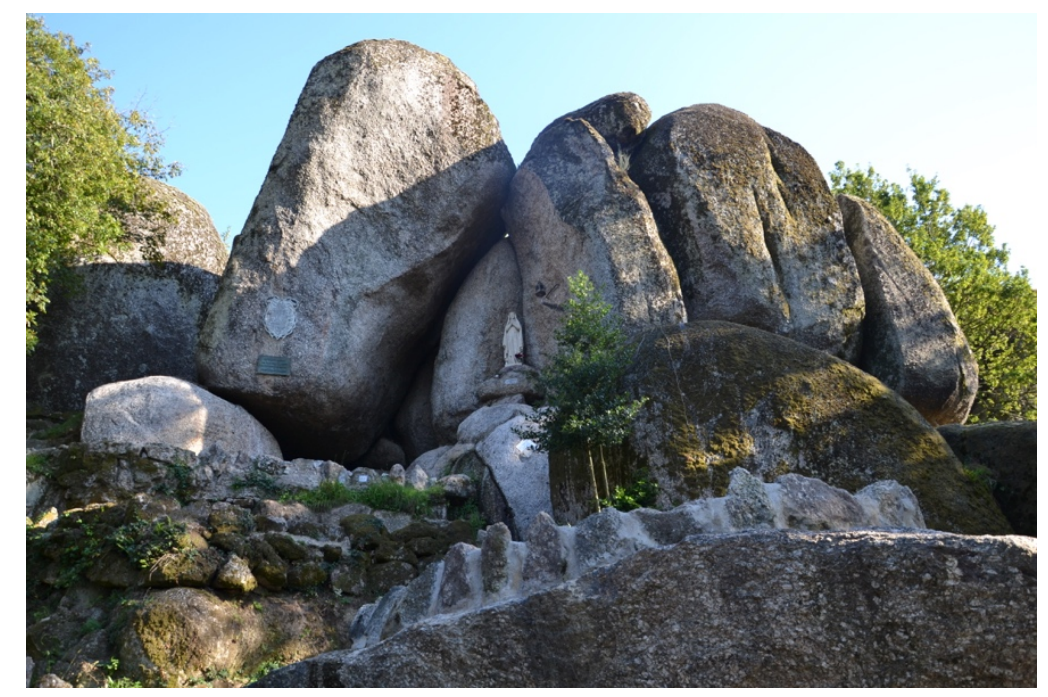

Figura 8: Gruta de Nossa Senhora de Lurdes.

e) A Gruta do Ermitão (Figura 9) é uma cavidade em rocha granítica, atualmente alterada, tendo-se construído uma capela no seu interior. É referido como o local onde um eremita teria habitado e teria iniciado o culto à Nossa Senhora do Carmo da Penha.
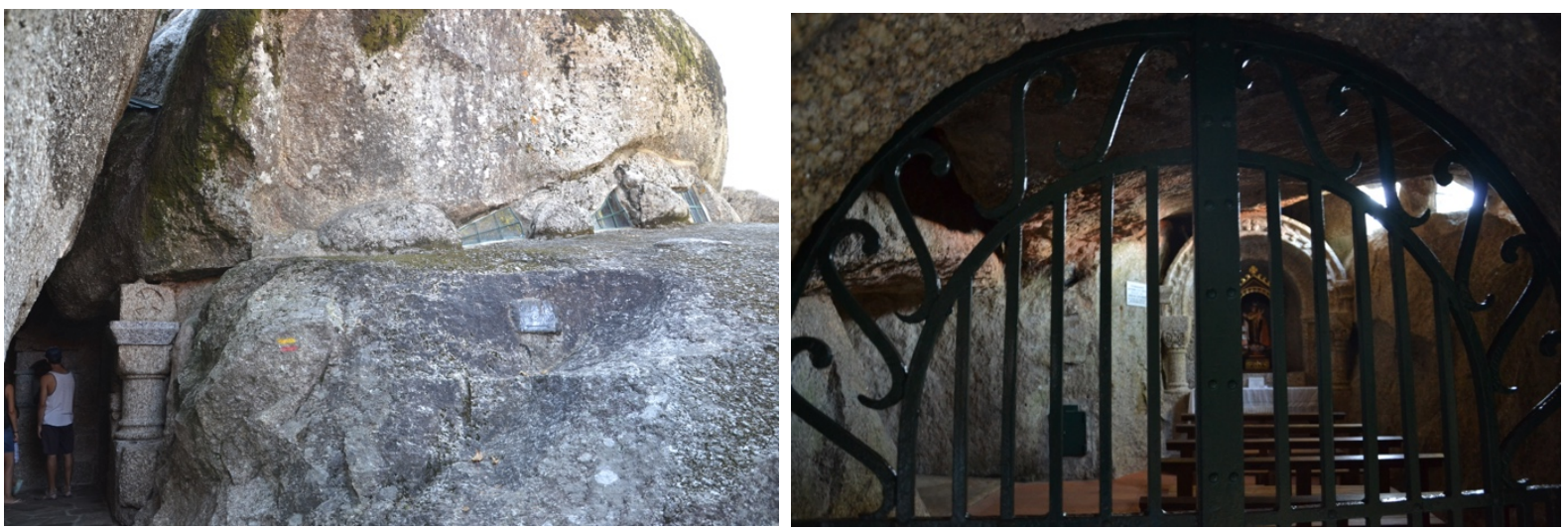

Figura 9: Gruta do ermitão.

Com base nos critérios inicialmente definidos procedemos à avaliação dos diversos elementos patrimoniais selecionados, obtendo-se, deste modo, a sua classificação por conjunto de valores e um indicador final ponderado que avalia a totalidade dos critérios (Tabela 1). 
Tabela 1: Avaliação do Património Geomorfológico da Serra da Penha

\begin{tabular}{|c|l|c|c|cc|}
\hline \multicolumn{7}{|c|}{ Avaliação } \\
\hline No & \multicolumn{1}{|c}{ Nome } & V. Intrínseco & V. Adicional & V. Uso e Gestão & Valor Total \\
\hline SG01 & Penedo suspenso & $(4,5) 0,90$ & $(11) 0,85$ & $(3,5) 0,70$ & $\mathbf{0 , 8 2}$ \\
\hline SG02 & Desfiladeiro labiríntico & $(4,17) 0,83$ & $(8,33) 0,64$ & $(3,5) 0,70$ & $\mathbf{0 , 7 3}$ \\
\hline SG03 & Pedra que abana & $(3,25) 0,65$ & $(7,83) 0,60$ & $(3) 0,60$ & $\mathbf{0 , 6 2}$ \\
\hline SG04 & Gruta de Nossa & $(3,83) 0,77$ & $(11,5) 0,89$ & $(3,5) 0,70$ & $\mathbf{0 , 7 8}$ \\
& Senhora de Lurdes & $(2,83) 0,57$ & $(7,17) 0,55$ & $(3,5) 0,70$ & $\mathbf{0 , 6 1}$ \\
\hline SG05 & Gruta do Ermitão & $(2,5)$ &
\end{tabular}

Nota: Os valores entre parênteses correspondem à soma absoluta dos critérios. Os valores fora dos parênteses são os normalizados.

A avaliação realizada, baseada nos critérios considerados no contexto da metodologia utilizada, refletem a importância que os diversos elementos geomorfológicos selecionados apresentam, destacando-se alguns, quer pelo seu valor intrínseco, quer pelo valor adicional. Neste último, evidencia-se a importância dos aspetos culturais e da relação que os valores histórico-culturais e religiosos apresentam, num local que é, por excelência, um local de culto e de romarias.

Contudo, também os critérios relacionados com o valor ecológico aqui têm grande importância e relevância na avaliação de alguns destes sítios, reforçando o interesse de integrar os elementos da geodiversidade na proposta de criação da Paisagem Protegida Local.

Dos cinco sítios selecionados, constatamos que todos eles apresentam valores consideráveis, ainda que aqueles que revelam uma pontuação mais elevada, correspondente a uma valorização no conjunto dos diversos critérios, tenham sido o Penedo Suspenso, a Gruta de Nossa Senhora de Lurdes e o Desfiladeiro Labiríntico, respetivamente.

Contudo, tal como temos vindo a afirmar, não consideramos esta metodologia uma ferramenta de seleção ou eliminação dos elementos patrimoniais, devendo ser considerada no sentido da definição de prioridades nas estratégias de conservação e proteção, e, acima de tudo, de planeamento de medidas e instrumentos de divulgação, de adequação aos públicos-alvo ou na elaboração de materiais pedagógicos e ilustrativos (Vieira, 2014; Vieira et al., 2014).

\section{Conclusões}

A criação de áreas protegidas, em Portugal, tem ocorrido fundamentalmente com objetivos de proteção e preservação dos elementos bióticos e, nalguns casos, de manutenção de práticas culturais ancestrais, raramente prestando grande consideração pelos elementos abióticos, constituintes da geodiversidade.

A proposta que tem vindo a ser desenvolvida pelo Município de Guimarães, de constituir na área da Serra da Penha uma área de Paisagem Protegida Local, parte do pressuposto de considerar os elementos geopatrimoniais como fatores relevantes para a sua valorização, estando claramente incluídos nos seus objetivos e ações específicas a desenvolver. 
Neste contexto, e nesta fase preliminar, definem-se metodologias de avaliação do Património Geomorfológico, por forma a identificar os elementos com relevância para a referida proposta e definição de estratégias de geoconservação e de geopromoção a implementar.

Da avaliação realizada aos cinco sítios selecionados foi possível avaliar o valor específico de cada sítio selecionado, destacando-se nesta análise os sítios do Penedo Suspenso, da Gruta de Nossa Senhora de Lurdes e do Desfiladeiro Labiríntico como os de maior relevância na área em consideração.

\section{Agradecimentos}

Este trabalho foi cofinanciado pelo Fundo Europeu de Desenvolvimento Regional (FEDER) através do Programa Operacional COMPETE 2020 para a Competitividade e Internacionalização (POCl) e fundos nacionais da FCT no âmbito do projeto POCl01-0145-FEDER-006891 (FCT Ref: UID / GEO 04084/2019).

\section{Bibliografia}

Bento-Gonçalves, A., Vieira, A., Ferreira-Leite, F., Martins, J., Silva, D., Soares, V. (2011). Adaptaclima: Adaptação aos efeitos derivados das alterações climáticas. As Mudanças Climáticas e os Incêndios Florestais no Ave. Guimarães: AMAVE, 100. http://hdl.handle.net/1822/20489

Cendrero Uceda, A. (1996). El patrimonio geológico. Ideas para su protección, conservación y utilización. In: MOPTMA. El patrimonio geológico. Bases para su valoración, protección, conservación y utilización. (pp. 17-27). Madrid.

Dixon, G. (1995). Aspects of geoconservation in Tasmania: A preliminary review of significant Earth features. Report for Tasmania Parks and Wildlife Service and Australian Heritage Commission. Parks and Wildlife Service Tasmania. Occasional paper $\mathrm{n}^{\circ} .32$.

Figueiró, A. S., Vieira, A., Cunha, L. (2013). Património geomorfológico e paisagem como base para o geoturismo e o desenvolvimento local sustentável. CLIMEP - Climatologia e $\begin{array}{llll}\text { Estudos da } & \text { Paisagem, }\end{array}$ https://www.periodicos.rc.biblioteca.unesp.br/index.php/climatologia/article/view/7554

Gray, Murray (2004). Geodiversity. Valuing and conserving abiotic nature. Wiley.

Gray, Murray (2013). Geodiversity. Valuing and conserving abiotic nature. Second Edition. Wiley Blackwell.

Grandgirard, V. (1997). Geomorphologie et gestion du patrimoine naturel. La memoire de la Terre est notre memoire. Geographica Helvetica, 2, 47-52. https://doi.org/10.5194/gh-52$\underline{47-1997}$

Meireles, F., Fernandes, J., Salgado, R., Silva, P., Soares, S. (2017). Paisagem Protegida Local da Montanha da Penha. Bases para o plano de ação. Guimarães: CMG.

Oliveira, M. (2001). Modificações do uso do solo na Serra da Penha. Relatório de investigação. Guimarães: Universidade do Minho. 190 p.

Panizza, M., Piacente, S. (1993). Geomorphological assets evaluation. Zeitschrift fur Geomorphologie. N. F., Suppl. BD, 87, 13-18. 
Panizza, M., Piacente, S. (2003). Geomorfologia culturale. Bologna, Pitagora Editrice.

Pinto, A. (2011). Caraterização e valorização do Património Geológico da Penha (Guimarães, Norte de Portugal). Tese de Mestrado. Braga: Universidade do Minho.

Pralong, J.-P. (2005). A method for assessing tourist potential and use of geomorphological sites. Geomorphologie: relief, processus, environement, 11(3), 189-196. http://journals.openedition.org/geomorphologie/350

Reynard, E. (2005). Géomorphosites et paysages. Geomorphologie: relief, processus, environement, 11(3), 181-188. https://journals.openedition.org/geomorphologie/338

Reynard, E., Panizza, M. (2005). Géomorphosites: definition, evaluation et cartographie. Une introduction. Geomorphologie: relief, processus, environement, 11(3), 177-180. http://journals.openedition.org/geomorphologie/336

Sharples, C. (1993). A Methodology for the identification of significant landforms and geological sites for geoconservation purposes. Forestry Commission, Tasmania.

Serrano, E., Trueba, J. (2005). Assessment of geomorphosites in natural protected areas: the Picos de Europa National Park (Spain). Geomorphologie: relief, processus, environement, 11(3), 197-208. http://journals.openedition.org/geomorphologie/364

Vieira, A. (2008). A Serra de Montemuro. Dinâmicas geomorfológicas, evolução da paisagem e património natural. Dissertação de Doutoramento, Universidade de Coimbra. Disponível em: http://hdl.handle.net/10316/9006

Vieira, A. (2014). O Património Geomorfológico no contexto da valorização da geodiversidade: sua evolução recente conceitos e aplicação. Cosmos, 7(1), 28-59. http://hdl.handle.net/1822/34835

Vieira, A., Figueiró, A. S., Cunha, L. (2014) Metodologia de Avaliação do Património Geomorfológico: Aplicação à serra de Montemuro (Portugal). In: ATAS/Proceedings I Encontro Luso-Brasileiro de Património Geomorfológico e Geoconservação. (pp. 181-187). Coimbra: CEGOT.

Vieira, A., Costa, F. S., Bento-Gonçalves, A. (2019). Avaliação dos espaços verdes e hídricos do Município de Guimarães (Portugal). In: Diálogos Interdisciplinares nas ciências ambientais: ampliando olhares e Perspectivas, M. Carvalho et al. (Org.). (pp. 421-439). Sergipe: Editora UFS.

Vieira, A., Cunha, L. (2004). Património Geomorfológico - tentativa de sistematização. Actas do III Seminário Latino-americano de Geografia Física, CD- Rom, GMF07, Puerto Vallarta. Disponível em: http://hdl.handle.net/1822/35546

Vieira, A., Cunha, L. (2008). Património Geomorfológico no Portugal Central. Sua importância para a definição e valorização de áreas protegidas. Revista Geografia Ensino \& Pesquisa, Anais do V Seminário Latino-americano de Geografia Física, 12(1), 179-193. Disponível em: http://hdl.handle.net/1822/13785

Artigo recebido em/ Received on: 20/12/2019

Artigo aceite para publicação em/ Accepted for publication on: 29/12/2019 